\title{
CHARACTERIZATION OF AROMATIC HEPTAENE MACROLIDE ANTIBIOTICS BY HIGH PERFORMANCE LIQUID CHROMATOGRAPHY
}

\author{
W. MeChlinski and C. P. SChaffNeR* \\ Waksman Institute of Microbiology, Rutgers - The State University \\ P.O. Box 759, Piscataway, New Jersey 08854, U.S.A.
}

(Received for publication November 14, 1979)

\begin{abstract}
High performance liquid chromatographic (HPLC) procedures were utilized for the rapid and efficient separation and characterization of the aromatic heptaene macrolide group of antifungal antibiotics. The instrument utilized a $350 \mathrm{~nm}$ phosphor converted ultraviolet detector and a $\mu$ Bondapak $\mathrm{C}_{18}$ column packing. Optimum resolution of eleven commercial aromatic heptaene macrolide preparations was obtained with solvent systems consisting of mixtures of acetonitrile and $0.05 \mathrm{M}$ aqueous sodium citrate buffer, $\mathrm{pH}$ 5.3. The presence of two distinct types of aromatic heptaene macrolides with numerous well-defined individual components has been established.
\end{abstract}

The polyene macrolide antifungal antibiotics ${ }^{1,2)}$ are among the most abundant of microbial antibiotic products. Classified as tetraenes, pentaenes, hexaenes, and heptaenes according to the number of conjugated double bonds in the molecule, these antibiotics are generally recognized for their complexity and difficulty of characterization. In the past a number of different analytical procedures including paper chromatography, thin-layer chromatography and countercurrent distribution has been used for the separation and characterization of these complex antibiotics with varied but generally limited success. The separation of the aromatic subgroup of heptaene macrolides, in particular, by these techniques was most inadequate. Countercurrent distribution procedures at best permitted the gross separation of these antibiotics with several serious drawbacks including excessive time for resolution and product instability.

The technique of high performance liquid chromatography (HPLC) was first reported for the analysis of different polyene macrolide antibiotics in $1973^{3)}$ and later more fully described in 1974). The HPLC results with the non-aromatic heptaene macrolides such as amphotericin B and candidin clearly exceeded those obtained previously by other analytical procedures including countercurrent distribution. Preliminary HPLC studies $^{5)}$ with three closely related aromatic heptaene macrolides also indicated the potential of this analytical procedure in the characterization and differentiation of these numerous complex antibiotics.

The recent availability of more efficient HPLC column packing materials enabled further improvement in the resolution and characterization of all polyene macrolide antibiotics. The results of HPLC studies with eleven better known members of the aromatic heptaene group are reported here.

\section{Materials and Methods}

High performance liquid chromatograph

A noncommercial HPLC instrument previously described ${ }^{4)}$ was employed throughout these studies.

* To whom all correspondence should be addressed. 
A ready packed column containing $\mu$ Bondapak $C_{18}$ material (catalog \#DS 042, 27324; dimensions 1/4" O.D. $x 1^{\prime \prime}$ ) was obtained from Waters Associates, Inc. The UV detector was an LDC phosphor converted to a 350-nm UV monitor featuring an 8- $\mu 1$ cell and a double-beam optical system.

Mobile phase solvent systems

The optimal mobile phase, system A, consisted of a mixture of acetonitrile and $0.05 \mathrm{M}$ aqueous sodium citrate buffer ( $\mathrm{pH} 5.3$ ) in a ratio of $35: 65, \mathrm{v} / \mathrm{v}$, respectively. A second mobile phase, system $\mathrm{B}$, was similar to A except the ratio of acetonitrile to $0.05 \mathrm{M}$ sodium citrate buffer was $32: 68, \mathrm{v} / \mathrm{v}$, respectively. The final apparent $\mathrm{pH}$ of both solvent systems was 6.0 and was adjusted when needed with $1 \mathrm{~m}$ citric acid or sodium hydroxide in water. Certified (A.C.S.) grades of solvents and salts were used throughout. The mobile phase systems were degassed prior to use by the vacuum technique and kept at a constant room temperature.

\section{Column operation}

The $\mu$ Bondapak $\mathrm{C}_{18}$ column was maintained at a constant temperature of $30^{\circ} \mathrm{C}$ by means of a water circulator and jacket. The chromatograph was operated at pressures of 1,000 1,200 p.s.i. measured at the pump and at flow rates of $1.4 \sim 1.7 \mathrm{ml} / \mathrm{min}$. The attenuation of the ultraviolet detector was 0.02 unit full-scale (Aufs).

When new $\mu$ Bondapak $\mathrm{C}_{18}$ columns were employed, it was necessary to precondition the packing material to obtain optimum resolution. The effective treatment involved pumping $300 \sim 500 \mathrm{ml}$ of the mobile phase solvent system A through the column followed by repeated injections of $5 \sim 10 \mu \mathrm{g}$ aliquots of a polyene macrolide antibiotic. This procedure was very important and appeared to modify and stabilize the packing.

\section{Antibiotic preparations}

The aromatic heptaene macrolide antibiotics employed in these studies are as follows: Antibiotic DJ-400, Schering A. G., Berlin, West Germany; partricin, G. D. Searle \& Co., Chicago, Illinois, U.S.A.; hamycin and aureofungin, Hindustan Antibiotics, Ltd., Pimpri, Poona, India; trichomycin, Fujisawa Pharmaceutical Co., Ltd., Osaka, Japan; candimycin, Takeda Chemical Industries Ltd., Osaka, Japan; levorin, Leningrad Institute of Antibiotics, U.S.S.R.; ayfactin, Bristol Laboratories, Syracuse, New York, U.S.A.; ascosin, Commercial Solvents Corp., Terre Haute, Indiana, U.S.A.; candicidin, Penick, Lyndhurst, New Jersey, U.S.A.; and heptamycin, The Hebrew University, Jerusalem, Israel.

For the HPLC studies antibiotic stock solutions $(0.5 \mu \mathrm{g} / \mu \mathrm{l})$ were prepared by dissolving $10 \mathrm{mg}$ of each antibiotic in $2 \mathrm{ml}$ of dimethyl sulfoxide and diluting the resultant solution with $18 \mathrm{ml}$ of methanol. The sample, usually $1 \sim 5 \mu \mathrm{l}$ containing $0.5 \sim 2.5 \mu \mathrm{g}$ of antibiotic, was injected on-stream through the syringe injector.

\section{Results}

\section{Development of HPLC Conditions}

A significantly stronger absorption of the polyene macrolide antibiotics was observed on $\mu$ Bondapak $\mathrm{C}_{18}$ column packing material than on the previously used ${ }^{4)}$ VYDAC RP material. This necessitated the development of new mobile phase systems to take full advantage of the high efficiency packing. The choice of mobile phases for the separation of polyene macrolides in general and heptaene macrolides in particular was complicated, however, due to their high molecular weight, poor solubility and rather complex amphoteric and mixed hydrophilic-hydrophobic character easily affected by ionic concentration and $\mathrm{pH}$.

Mixtures of methanol or acetonitrile, varying to $80 \%$ of total volume, and $0.005 \sim 0.4 \mathrm{M}$ aqueous buffers in the $\mathrm{pH}$ range of $4 \sim 8.5$ were used as mobile phases in preliminary studies. The resolution of aromatic heptaene macrolides at $\mathrm{pH} 8.5$, the upper limit of the $\mu$ Bondapak $\mathrm{C}_{18}$ packing material, was generally poor, regardless of the ratio of organic solvent to buffer and of buffer concentration. 
At neutrality an improvement in separation was observed, and the retention times of the antibiotics were in an inverse relation to buffer concentrations.

The best separation and resolution of antibiotic components were obtained at acidic conditions, between $\mathrm{pH} 5$ and 6.5. In this $\mathrm{pH}$ range the effect of buffer concentration was also pronounced. A decrease in buffer concentration below what appeared to be the optimal level of 0.05 molar caused a significant increase in retention time and a deterioration of resolution. In one example the increase in retention time was $220 \%$ when the buffer concentration was lowered from 0.05 to 0.025 molar at pH 6 with other parameters being constant. Only a small decrease in retention time was observed with the decrease in $\mathrm{pH}$ of the mobile phase from 6.5 to 5 . Below $\mathrm{pH} 5$ the retention time increased for some of those antibiotics studied, and the separation usually deteriorated significantly.

In the present study the optimal mobile phase, designated as solvent system A, consisted of acetonitrile and $0.05 \mathrm{M}$ aqueous sodium citrate buffer, $\mathrm{pH} 5.3(35: 65, \mathrm{v} / \mathrm{v})$ with a final mixture $\mathrm{pH} 6.0$. The retention time and resolution of all aromatic heptaene macrolide antibiotics could be controlled by changing the ratio of solvents in the mobile phase mixture either manually or by a gradient device. A $3 \%$ decrease in acetonitrile content in mobile phase $A$ to $32: 68, \mathrm{v} / \mathrm{v}$ resulted in an approximate doubling of the retention time and an appreciable increase in resolution of fast moving antibiotic components. This mobile phase was designated as solvent system B.

When methanol was substituted for acetonitrile in the HPLC mobile phase, the separation and resolution of the aromatic heptaene macrolides was noticeably poorer. The optimal mobile phase found was methanol - $0.04 \mathrm{M}$ aqueous monobasic potassium phosphate $(3: 1, \mathrm{v} / \mathrm{v})$ adjusted to $\mathrm{pH} 6$ with phosphoric acid. No significant differences were observed between potassium phosphate and sodium citrate buffers with either methanol or acetonitrile.

\section{Indexing of Antibiotic Components}

Many of the antibiotic components from the various aromatic heptaene macrolide preparations exhibited identical retention times. To facilitate a convenient and precise comparison of the parent antibiotics, the peaks were numbered 1 to 13 in the order of increasing retention time. Measurements of retention times were made under identical isocratic conditions for all antibiotics. With very closely positioned components the indexing was aided by multiple measurements of consecutive separation curves obtained under higher resolution conditions such as with mobile phase B. Admixtures at a different ratio of antibiotics in question were also separated and compared when necessary. Table 1 summarizes the appropriate retention times determined for all indexed components in both mobile phase solvent systems.

Separation and Comparison of Aromatic Heptaenes by HPLC

The representative HPLC separation curves

Table 1. Comparison of retention times of heptaene macrolide indexed components in mobile phase solvent systems A and B

\begin{tabular}{l|c|c}
\hline \multirow{2}{*}{$\begin{array}{c}\text { Component } \\
\text { index }\end{array}$} & \multicolumn{2}{|c}{ Retention time (min. \pm 0.2$)$} \\
\cline { 2 - 3 } & Mobile phase A & Mobile phase B \\
\hline 1 & 3.5 & 6.4 \\
2 & 4.1 & 7.5 \\
3 & 4.5 & 8.2 \\
4 & 5.0 & 9.1 \\
5 & 5.4 & 9.9 \\
6 & 6.0 & 11.5 \\
7 (a) & 6.7 & 13.3 \\
8 & 7.0 & 14.2 \\
9 (b) & 7.2 & 16.5 \\
10 & 8.5 & 18.1 \\
11 (c) & 9.2 & 20.5 \\
12 & 10.0 & 22.6 \\
13 (d) & 11.8 & 24.0 \\
\hline
\end{tabular}


shown in the present study were obtained using antibiotics from commercial sources and from different research laboratories indicated earlier.

The commercial antibiotics include candicidin, levorin, hamycin, trichomycin, aureofungin, candimycin and partricin. Different lots of these antibiotics were found to be more uniform in regard to purity and composition of individual HPLC components than were the remaining antibiotics produced in research laboratories. Variations between different lots of the same antibiotics must be considered during any comparative study of the aromatic heptaene members.

Fig. 1. HPLC of partricin, ayfactin, hamycin and trichomycin. Mobile phase solvent system A.

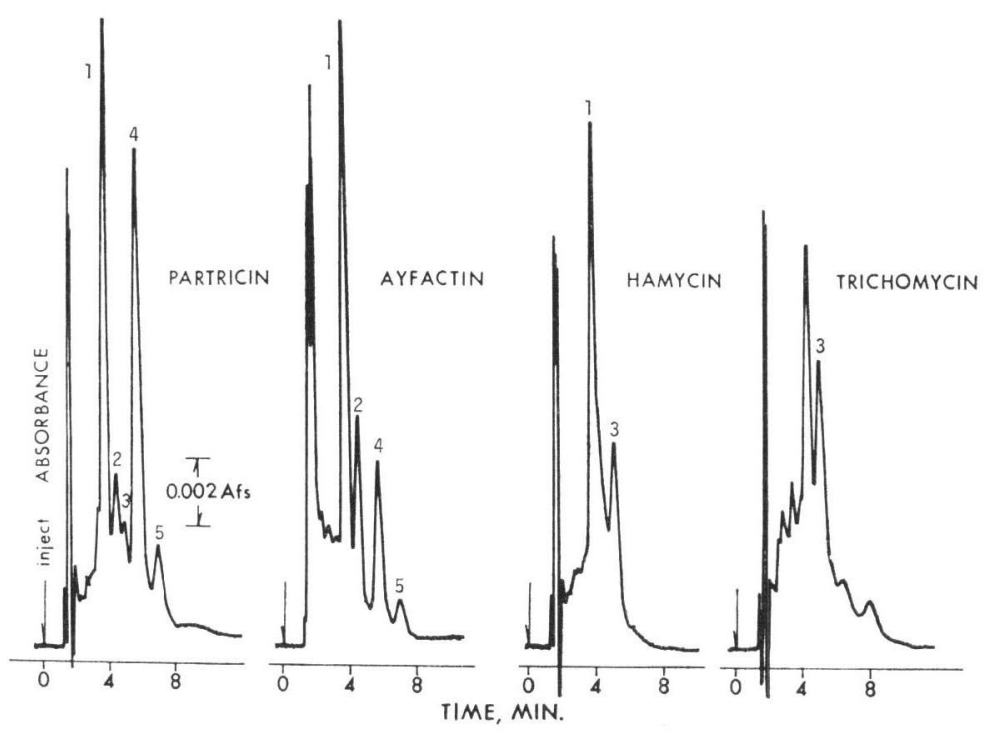

Fig. 2. HPLC of aureofungin, candimycin, and antibiotic DJ-400. Mobile phase solvent system A.

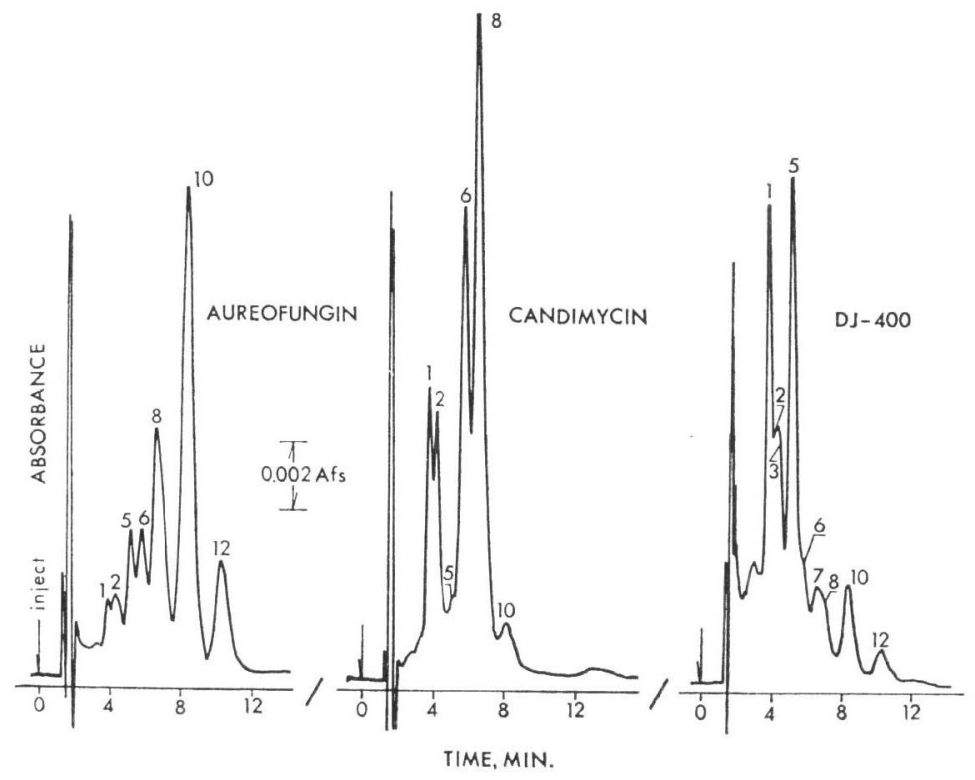


Fig. 3. HPLC of antibiotic DJ-400 and partricin. Mobile phase solvent system B.
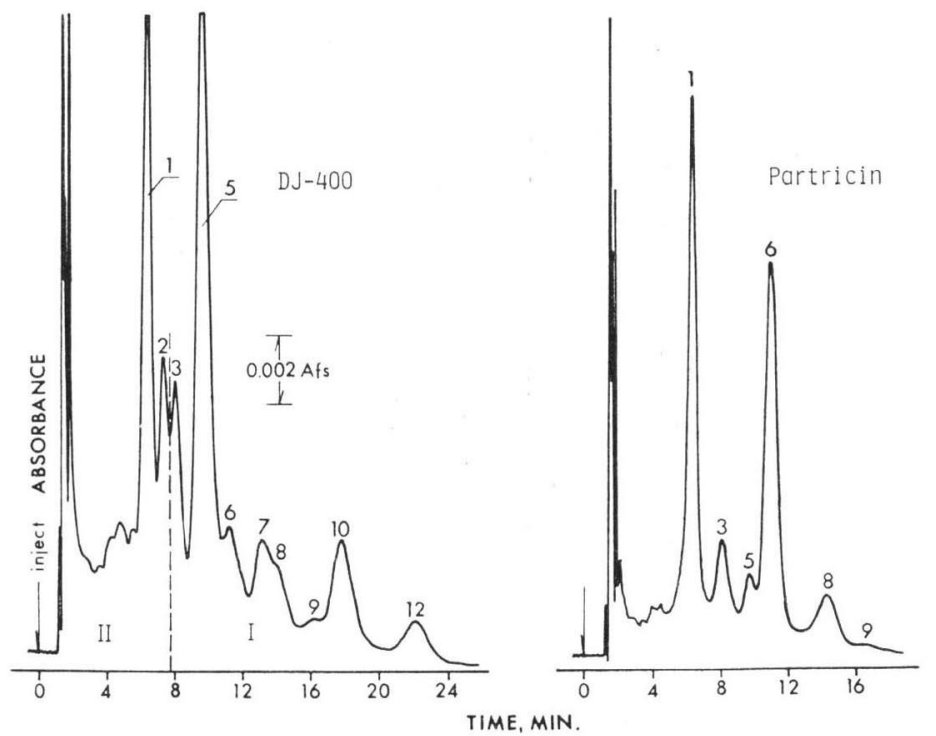

The HPLC separations in solvent system A of partricin ${ }^{()}$, ayfactin ${ }^{7)}$, hamycin ${ }^{8)}$ and trichomycin $^{9)}$ are shown in Fig. 1 and that of aureofungin $^{10)}$, candimycin ${ }^{11)}$ and antibiotic DJ-400 ${ }^{12)}$ in Fig. 2. A separation at a higher resolution in the mobile phase $\mathrm{B}$ for partricin is also shown in Fig. 3 and for hamycin and trichomycin in Fig. 4. The increased resolution of components in mobile phase $\mathrm{B}$ is particularly evident for hamycin.

The potential of HPLC for the analysis of different aromatic heptaenes is well illustrated by Fig. 5, which depicts individual and superimposed separation curves for trichomycin, aureofungin 'and candicidin.

Fig. 4. HPLC of hamycin and trichomycin. Mobile phase solvent system B.

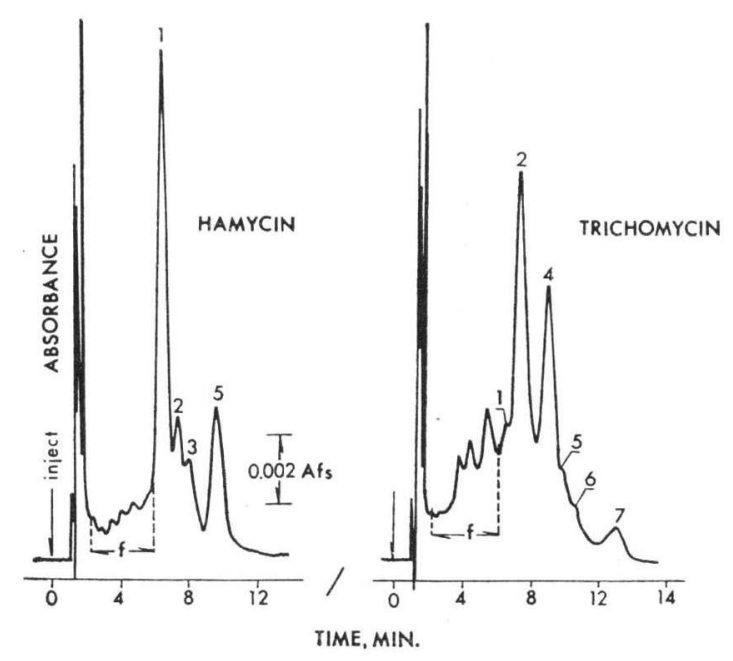

A comparison of HPLC separation curves obtained under identical conditions for a group of four extremely similar, if not identical, antibiotics candicidin ${ }^{13)}$, levorin ${ }^{14)}$, ascosin ${ }^{15)}$ and heptamycin ${ }^{16)}$ is shown in Fig. 6. The different indexing of components introduced for this group of antibiotics was to facilitate their quick identification and to emphasize the many unique properties of the members. The retention times of the main components $a, b, c$ and $d$, however, were found to be identical to the components 7, 9, 11 and 13, respectively, in the common indexing system. In addition a group of minor components $\mathrm{f}$ (fast moving) and s (slow moving) is evident in the separation curve in Fig. 6. A close inspection of the HPLC separation curve for ascosin reveals also the presence of two additional shoulders, one between components $\mathrm{b}$ and $\mathrm{c}$ and the other between $\mathrm{c}$ and $\mathrm{d}$. 
Fig. 5. HPLC of trichomycin, aureofungin, and candicidin and their comparison.

Mobile phase solvent system A.

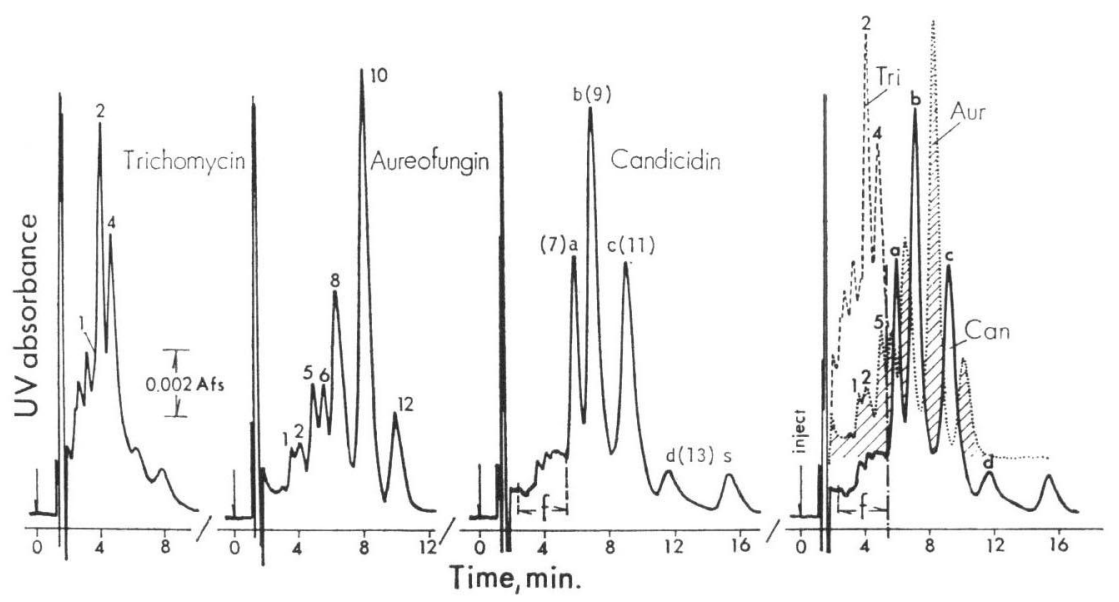

Fig. 6. Comparative HPLC of ascosin, levorin, candicidin and heptamycin.

Mobile phase solvent system A.

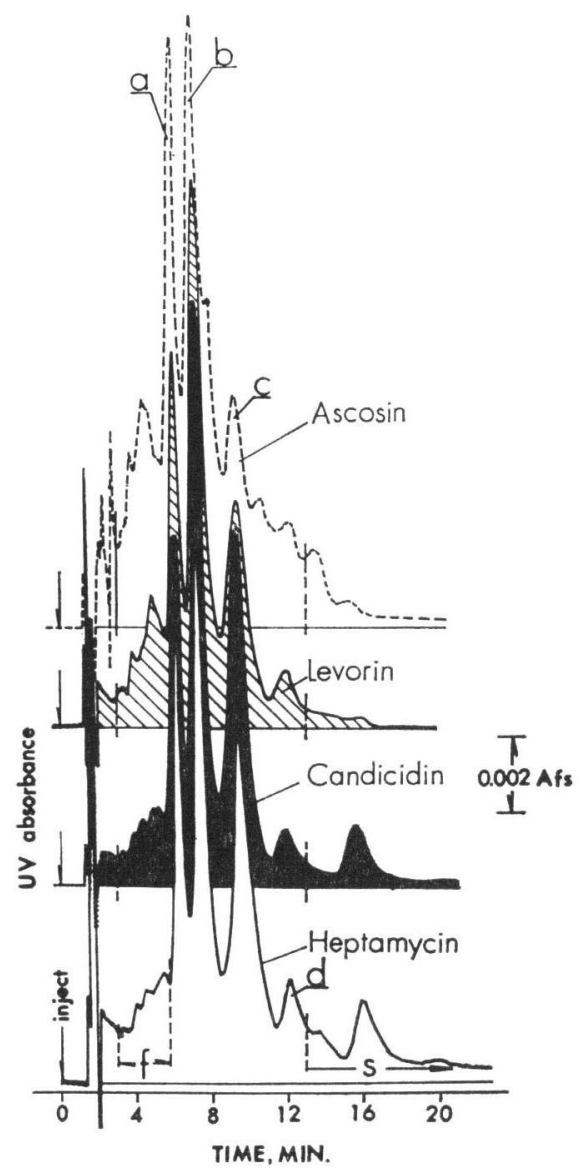

The close apparent similarity of the antibiotics shown in Fig. 6 prompted us to examine the HPLC separation curves for admixtures of these compounds. The results of this study involving the best known members of the group, candicidin and levorin are presented in Fig. 7. Similar studies were also made for all other closely related antibiotics.

The individual components detected by HPLC in each antibiotic studied in this report are listed in Table 2 to facilitate characterization and comparison. References are also made in Table 2 to the appropriate figures on which the quantitative measurements were based. All characteristic main components found in the parent antibiotics, determined as those present in excess of $10 \%$ of peak area, are underlined for easy identification. In addition the $f$ and $s$ components are identified and quantitated. These components represent impurities and depend heavily on the origin of the antibiotics and the purification method employed and should not be used in characterization or in comparison of the parent compounds. 
Fig. 7. HPLC of candicidin and levorin and their mixture.

Mobile phase solvent system A.

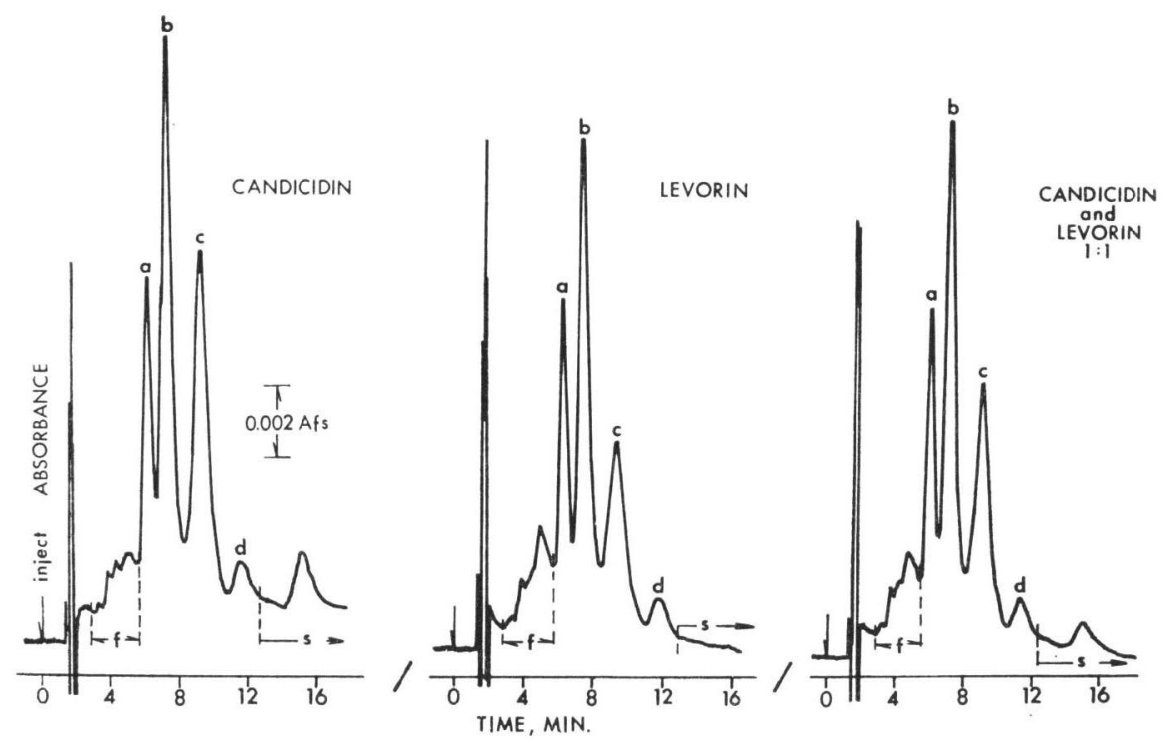

Table 2. Comparison of aromatic heptaene antibiotics by HPLC based on the type and content of detected components.

\begin{tabular}{|c|c|c|c|c|c|c|c|c|c|c|c|c|c|c|c|c|}
\hline \multirow{2}{*}{ Antibiotic } & \multirow{2}{*}{$\underset{\#}{\text { Fig. }}$} & \multicolumn{15}{|c|}{ Components found by HPLC in $\%$ of peak area } \\
\hline & & $\mathrm{f}$ & 1 & 2 & 3 & 4 & 5 & 6 & 7 & 8 & 9 & 10 & 11 & 12 & 13 & $\mathrm{~s}$ \\
\hline & & & & \multicolumn{2}{|c|}{ Group I } & & & & & & & & & & & \\
\hline Ayfactin & 1 & 18.6 & 43.7 & - & 13.7 & - & 3.8 & 16.4 & & 3.8 & & & & & & \\
\hline Partricin & 1 & 9.9 & 29.4 & - & $\underline{9.5}$ & - & 5.8 & 32.9 & - & 8.2 & 4.3 & & & & & \\
\hline Partricin & 3 & 8.8 & 36.6 & - & 10.7 & - & 5.9 & 29.0 & - & 6.9 & 2.1 & & & & & \\
\hline Trichomycin & 4 & 28.1 & 8.9 & 27.2 & - & 21.1 & 5.4 & 4.9 & 4.4 & & & & & & & \\
\hline Hamycin & 4 & 18.9 & 42.2 & 10.0 & 10.0 & - & 18.9 & & & & & & & & & \\
\hline Antib. DJ-400 & 2 & 12.2 & 19.4 & 8.2 & 8.2 & - & 25.3 & 4.0 & 5.3 & 5.3 & - & 8.4 & - & 3.7 & & \\
\hline Antib. DJ-400 & 3 & 12.5 & 18.8 & 7.2 & 8.4 & - & 25.1 & 6.6 & 5.3 & 3.5 & 2.4 & 7.2 & - & 3.2 & & \\
\hline Candimycin & 2 & 3.7 & 11.0 & 8.9 & - & - & 4.1 & 24.6 & - & 38.2 & - & 4.4 & 2.6 & 2.6 & & \\
\hline \multirow[t]{2}{*}{ Aureofungin } & 2 & 3.6 & 4.0 & 5.2 & - & - & 7.6 & 8.8 & - & $\underline{21.3}$ & - & $\underline{37.1}$ & - & $\underline{12.4}$ & & \\
\hline & & & & \multicolumn{2}{|c|}{ Group II } & & & & $\mathrm{a}$ & & b & & c & & d & \\
\hline Ascosin & 6 & 15.4 & & & & & & & 19.9 & - & $\underline{27.2}$ & $\underline{10.3}$ & $\underline{11.1}$ & 5 & 6.2 & 4.8 \\
\hline Candicidin & 7 & 12.0 & & & & & & & 16.5 & - & 31.9 & - & 25.6 & - & 6.8 & 7.2 \\
\hline Heptamycin & 6 & 10.9 & & & & & & & 15.6 & - & 23.1 & - & 24.4 & - & 5.9 & 19.2 \\
\hline Levorin & 7 & 15.8 & & & & & & & 21.4 & - & $\overline{36.3}$ & - & 21.4 & - & 5.1 & - \\
\hline
\end{tabular}

\section{Discussion}

The results of the present study summarized in Table 2 clearly reveal that the aromatic heptaene macrolides fall into two distinct classes represented by such antibiotics as ayfactin (partricin), aureofungin, trichomycin, hamycin, candimycin, and antibiotic DJ-400 in one class and the candicidin group (levorin, ascosin, and heptamycin) in the second class. Within each class numerous repeating and 
distinct antibiotic components are to be found in varying proportions. This variation in the proportion of components might very well account for any observed differences in biological and chemical properties among members of each class of aromatic heptaene macrolides.

The aromatic heptaene macrolides have long been the topic of discussions regarding their identity. In particular, the comparison of candicidin with levorin has been the subject of much concern. Although the first report on levorin ${ }^{14)}$ presented evidence for the differentiation of levorin from candicidin, other studies $^{17)}$ involving countercurrent distribution procedures suggested their identity. The more recent HPLC studies ${ }^{5,18)}$ also supported the hypothesis that candicidin and levorin were identical. The results of the current HPLC studies clearly prove their identity as complexes of identical components but with variations of component proportions that might be easily expected with different lots of the same antibiotic. The identity of heptamycin to candicidin has also been established. Ascosin appears to be more complex due to the presence of additional components.

Extensive taxonomical studies have been carried out directly comparing Streptomyces griseus and S. levoris, known to produce candicidin and levorin, respectively, (Dr. RUTH E. Gordon, Waksman Institute of Microbiology, Rutgers University, personal communication, 1979). These microorganisms were found to be essentially identical and at best exhibited only strain differences. With macroscopic and microscopic examination of the cultures grown on several media it was observed that with only slight differences in the appearance of the aerial hyphae these microorganisms were equivalent. Chromatographic analyses of whole cell hydrolysates revealed the presence of LL-diaminopimelic acid in both cases. Both microorganisms also gave equivalent reactions with 50 different physiological tests.

The comparison of ayfactin and partricin by HPLC strongly suggest their identity. Differences in the proportions of individual antibiotic components might very well explain any observed differences in their chemical or biological properties. Here again it is interesting to note that the producing microorganisms in both cases, strains of Streptomyces aureofaciens also coproduce a tetracycline antibiotic. Trichomycin clearly differs from hamycin and all other studied antibiotics by the presence of a unique component 4. Antibiotics DJ-400, candimycin and aureofungin appear to have numerous common components but differ in their relative amounts.

It should be emphasized that only the difference in observed HPLC retention times was applied for the comparison of individual components of the aromatic heptaene macrolides. This has its obvious limitation. Nevertheless, the HPLC technique presented here is by far the most sensitive and rapid procedure for the analysis of aromatic heptaene macrolide antibiotics aside from all other classes of polyene macrolides. The HPLC technique is superior to all other analytical procedures used to date including paper, column and thin-layer chromatography and countercurrent distribution.

\section{Acknowledgements}

The authors wish to acknowledge the research support from the National Institutes of Health through Public Health Service Grants AI-2095 and AI-12602.

\section{References}

1) Hamilton-Miller, J. M. T.: Chemistry and biology of the polyene macrolide antibiotics. Bacteriol. Rev. 37: 166 196, 1973

2) Keller-Schierlein, W.: Chemie der Makrolid-antibiotica. Progr. Chem. Org. Nat. Prod. 30: 313 460, 1973

3) Mechlinski, W. \& C. P. SChaffner: HPLC of heptaene antifungal antibiotics. A new method for separation and comparison. Abstracts 13th ICAAC Conference, Washington, D.C., paper 143, September, 1973

4) Mechlinski, W. \& C. P. Schaffner: Separation of polyene antifungal antibiotics by high-speed liquid chromatography. J. Chromatogr. 99: 619 633, 1974

5) HANSen, S. H. \& M. Thomsen: Comparison of candicidin, levorin and trichomycin by means of highperformance liquid chromatography. J. Chromatogr. 123: 205 211, 1976

6) Bruzzese, T.; I. Binda, A. Dinardo, G. Ghielmetti \& M. Riva: Partricin methyl ester, a semisynthetic 
polyene antibiotic. Experientia 28: 1515 1516, 1972

7) Kaplan, M. A.; B. Heinemann, I. Mydlinski, F. H. Buckwalter, J. Lein \& I. R. Hooper: An antifungal substance (AYF) produced by a strain of Streptomyces aureofaciens. Antibiot. \& Chemoth. 8: 491 495, 1958

8) Thirumalachar, M. J.; S. K. Menon \& V. V. Bhatt: Hamycin, a new antifungal antibiotic. I. Discovery and biological studies. Hindustan Antibiot. Bull. 3: 136 138, 1961

9) Hosoya, S.; N. Komatsu, M. Soeda, T. Yamaguchi \& Y. Sonoda: Trichomycin, a new antibiotic with trichomonadicidal and antifungal activities. J. Antibiotics 5: $564 \sim 566,1952$

10) Thirumalachar, M. J.; P. W. Rahalkar, R. S. Sukapure \& K. S. Gopalkrishnan: Aureofungin, a new heptaene antibiotic. I. Microbiological studies. Hindustan Antibiot. Bull. 6: 108 111, 1964

11) Shibata, M.; M. Honjō, Y. Tokur \& K. Nakazawa: On a new antifungal and antiyeast substance, candimycin, produced by a streptomyces. J. Antibiotics 7, Ser. B: 168, 1954

12) Bohlmann, F.; E. V. Dehmlow, H.-J. Neuhahn, R. Brandt \& B. Reinicke: Neue Heptaen-makrolide. 1. Charakterisierung und Abbau. Tetrahedron 26: $2191 \sim 2198,1970$

13) Lechevalier, H.; R. F. Acker, C. T. Corke, C. M. Haenseler \& S. A. Waksman: Candicidin, a new antifungal antibiotic. Mycologia 45: $155 \sim 171,1953$

14) Borowski, E.; M. Malyshina, S. Soloviev \& T. Ziminski: Isolation and characterization of levorin A and B, the heptaenic macrolide antifungal antibiotics of aromatic subgroup. Chemotherapia 10: 176 194, $1965 / 66$

15) Hickey, R. J.; C. J. Corum, P. H. Hidy, I. R. Cohen, U. F. B. Nager \& E. Kropp: Ascosin, an antifungal antibiotic produced by a streptomycete. Antibiot. \& Chemoth. 2: 472 483, 1952

16) Henis, Y.; N. Grossowicz \& M. Aschner: Heptamycin, an antifungal and antiprotozoal antibiotic. Bull. Res. Council Israel E6: vii viii, 1957

17) Bosshardt, R. \& H. Bickel: Auf Kenntnis von Levorin A und Candicidin. Experientia 24: 522 524, 1968

18) Helboe, P.; M. Thomsen \& S. H. HAnSEN: Improved high-performance liquid chromatographic method for the comparison of heptaene macrolide antibiotics. J. Chromatogr. 189: 249 254, 1980 